\title{
Laser Induced Titanium and Tungsten Coating on 304 Stainless Steel Surfaces for Wear Resistant Improvement
}

\author{
Jinkui Dong ${ }^{1}$, Gang Niu ${ }^{1}$, Haofei $\mathrm{Zhi}^{1}$, Xingang Cao ${ }^{1}$, Yongtao $\mathrm{Li}^{1}$, Shilong $\mathrm{Liu}^{1 *}$, Xiaokai $\mathrm{Nie}^{1}$, Xuekang $\mathrm{Si}^{2}$ \\ ${ }^{1}$ China coal third construction (group) co. LTD., Suzhou, Anhui 234000, China \\ ${ }^{2}$ College of Mechanical Engineering, Tianjin University of Science \& Technology, Tianjin 300222,China
}

\begin{abstract}
Laser cladding is a tmenkind of surface treat technology with good prospects for application. By using laser cladding technology, the influence of 304 stainless steel cladding layer on its hardness and wear resistance was explored. This paper studied on different Ti and W ratio of the content of coating on 304 stainless steel. The micro-hardness and wear resistance were compared before and after the coating on the materials. The results represent that the wear property of some cladding layers was improved, which provides some theoretical references for the preparation of composite cladding reinforced of stainless steel surfaces.
\end{abstract}

\section{Introduction}

The application of laser in surface strengthening of metal materials has developed rapidly in recent years, such as laser phase-change hardening, laser alloying, and laser cladding[1,2]. Laser cladding technology is an important surface modification method to enhance the wear resistance[3].Laser deposition is a new technology developed in the 70's, it was based on the laser beam as a heat source, the work-piece surface coating a layer of metal or alloy powder, formation and substrate material performance make it totally different surface deposition layer, deposited layer and the substrate form the metallurgical bonding, choose different deposition layer material, can make the deposited layer to achieve compact structure, small grain size, hardness, wear resistance, corrosion resistance and other excellent performance[4]. Common forms of wear are mainly adhesion wear, abrasive wear and contact fatigue wear and corrosion wear and so on, the increase of toughness and strength of the material enhance the thermal fatigue, impact resistant, corrosion resistant[5], the performance of laser cladding technology for preparation of advanced coating technology has been widely used in the process of strengthening and repairing of metal components, the technology with high cooling rate, low dilution rate, and the advantages of smaller heat affected zone [6]. Although the CW laser is widely applied in the laser surface modification, there is a lack of research on the use of pulsed lasers in this research field, due to the short pulse width, high peak power, pulse laser can produce high enough melting depth, at the same time, it can greatly improve the cooling rate of molten pool [7].

The 304 stainless steel is a widely used chrome-nickel stainless steel with good low temperature strength and mechanical properties, as well as low hardness and poor abrasion resistance[8]. The 304 stainless steel to austenitic stainless steel, it has good plasticity and 
toughness and the cold workability, in oxidizing acid and the atmosphere, water, steam and other mediums has good corrosion resistance, is quite a useful type of steel, compared with conventional surface coating technology, laser coating has the coating composition is hardly affected by the interference of substrate composition and coating thickness can be controlled accurately, the combination of coating and substrate is metallurgical combination, small dilution degree, heat deformation is small, heat effect zone also is very small, the whole process is easy to implement online automatic control [9].

$\mathrm{Ti}$ as a kind of multiphase composite ceramic strengthening phase, has both the advantages of $\mathrm{TiC}$ and TiN, with high hardness, resistance to oxidation, corrosion resistance, abrasion resistance and other characteristics, by the wide attention of researchers both at home and abroad. By using laser cladding method preparation of Ti coating with substrate is metallurgical combination, low dilution degree, rapid heating and cooling makes characteristics of tissue refinement[10]. Tungsten alloy has high density, strength, low thermal expansion coefficient, corrosion resistance and good mechanical working and other combination properties[11].

The commonly used method of 304 stainless steel as substrate, before coating to laser texture substrate, the purpose is to strengthen the adhesion between coating and substrate, makes a better connection between substrate and coating [12]. Using the method of preset powder in 304 stainless steel samples with different $\mathrm{Ti}$ and $\mathrm{W}$ ratio of the content of coating, through a microscope, micro-hardness and wear resistance test method for sample analysis. This method of preparation of 304 stainless steel coating process is simple, short cycle, high efficiency, less energy consumption, conditions, easy control, easy to realize automation production, etc, in this way will be getting good performance in the 304 stainless steel surface of metal composite materials, it provides a theoretical reference for the industrial preparation of composite coatings to strengthen the surface of stainless steel materials.

\section{Materials and experimental procedures}

The substrate material uses 304 stainless steel, and the chemical composition of 304 stainless steel sample is

shown in Table 1 [13]. The sample size is $15 \mathrm{~mm} * 15$ $\mathrm{mm} * 1.5 \mathrm{~mm}$. Before laser cladding, the oxide layer and dirt on the surface shall be removed with sandpaper and cleaned with anhydrous ethanol.

Table 1. Chemical composition of 304 stainless steel (Wt. \%)

\begin{tabular}{|c|c|c|c|c|c|c|c|}
\hline C & $\mathrm{Cr}$ & $\mathbf{N i}$ & Si & Mn & $\mathbf{P}$ & $\mathbf{S}$ & $\mathrm{Fe}$ \\
\hline 0.06 & $\begin{array}{l}17 \\
08\end{array}$ & $\begin{array}{l}8 . \\
36\end{array}$ & $\begin{array}{l}0 \\
63\end{array}$ & $\begin{array}{l}0 . \\
70\end{array}$ & $\begin{array}{ll}0 . & 0 \\
24 & \end{array}$ & $\begin{array}{l}\mathrm{O} \\
02\end{array}$ & Margin \\
\hline
\end{tabular}

The $\mathrm{W}$ and Ti powder were used for coating materials, and different weight percentages were used for the two materials as shown in Table 2. The prepared powder is ground into fine particle size and mixed evenly, the area of the coating for 225 was, two kinds of powder coating in the total mass of the $0.0512 \mathrm{~g}$, the preset powder method is adopted, after the powder evenly, cover with black tape to increase its heat absorption.

Table 2. W and Ti powder composition(Wt.\%)

\begin{tabular}{|l|l:l:l:l:l:l:l:l|l|l|}
\hline Group & $\mathbf{1}$ & $\mathbf{2}$ & $\mathbf{3}$ & $\mathbf{4}$ & $\mathbf{5}$ & $\mathbf{6}$ & $\mathbf{7}$ & $\mathbf{8}$ & $\mathbf{9}$ \\
\hline $\mathrm{W}$ & 0 & 0.1 & 0.2 & 0.3 & 0.4 & 0.5 & 0.6 & 0.7 & 0.8 \\
\hdashline $\mathrm{Ti}$ & 1 & 0.9 & 0.8 & 0.7 & 0.6 & 0.5 & 0.4 & 0.3 & 0.2 \\
\hline
\end{tabular}

Experiments using wavelength of $532 \mathrm{~nm}$ (green light in the visible light range) of nanosecond laser, the output power of $10 \mathrm{~W}$, mark minimum line width $0.02 \mathrm{~mm}$, in the experiment of laser beam scanning speed, spacing and current can be adjusted. In the laser cladding test, the power is $10 \mathrm{~W}$, the scanning speed is $8 \mathrm{~mm} / \mathrm{s}$, the spot diameter is $0.02 \mathrm{~mm}$, and the current is $45 \mathrm{~A}$.

After cladding, the sample was cut into small pieces of $15 \mathrm{~mm} * 15 \mathrm{~mm} * 1.5 \mathrm{~mm}$ by linear cutting, and the section structure of the coating was observed and analyzed under the CX40M orthopedic metallographic microscope. The wear test is carried out on a dual disk metallographic polishing machine, the rotation speed is $600 \mathrm{r} / \mathrm{min}$, sand paper is $1000 \mathrm{P}$, the load is consistent, the load time is $3 \mathrm{~min}$, and the water is continuously added during experiments. Wearing and weight loss measurements were carried out on the electronic scale of one-thousandth of Aohaoshi. The micro-hardness of the coating was tested by means of Rockwell hardness tester, which loaded $60 \mathrm{~kg}$, and loading time is $5 \mathrm{~s}$.

\section{Results and discussion}




\subsection{Analysis of microstructure morphology of cladding layer}

Samples after the laser cladding process, The microstructure was observed by $\mathrm{CX} 40 \mathrm{M}$ orthopedic metallographic microscope, after cladding processing of the sample from the table and presents three different structural areas, the surface is cladding region, afterwards is heat affected zone and the bottom as substrate. The cross section of the sample microstructure is shown in Figure 1. The cladding is not well combined with the substrate, and there are some defects such as cracks and pores. The thickness of the cladding is about $50 \mu \mathrm{m}$, at the junction of the cladding layer and the thermal influence zone of the substrate, there exists a transition zone of continuous gray light zone with a width of $1 \sim 18$ $\mu \mathrm{m}$, which is caused by the extremely fast cooling rate during laser cladding treatment. The existence of this strip ensures the metallurgical bonding between the cladding layer and the substrate.

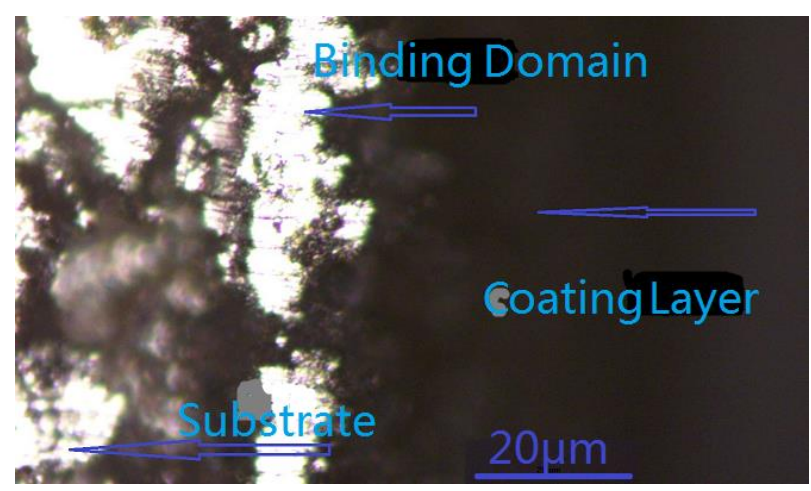

Figure 1. Cross section of microstructure.

Surface morphology of 304 stainless steel and each group of cladding layers are shown in Figure 2, a、 b、 c、 d、 e, $\mathrm{f} 、 \mathrm{~g} 、 \mathrm{~h} 、 \mathrm{I} 、 \mathrm{j}$ respectively is 304 stainless steel and $1 、 2 、 3 、 4 、 5 、 6 、 7 、 8 、 9$ groups of the surface rupture of the sample. Figure. 2 there is no typical dendritic structure in the cladding layer in the cladding zone, and the growth direction of dendritic is not obvious, and the structural characteristics of the cladding layer in the sample are not much different. The area of substrate, the microstructure is shown in Figure 2 a, the base material is 304 stainless steel, and the microstructure structure is composed of pearlite and ferrite, due to the area far from laser irradiation on the surface of the substrate, and the heat transfer effect in the laser cladding process. From $b 、 c 、 d 、 e 、 f 、 g 、$ $\mathrm{h}$ 、 I and $\mathrm{j}$ figure can be seen that they have a common characteristic is the grain not completely melt, specimen surfaces absorb less heat, substrate overheat degree is small, the temperature gradient in the liquid phase of crystallization is small. Thus growth time of the grain is short, the liquid phase has solidified into a solid phase before the grain grows further, therefore, the cladding layer presents small and sparse microstructure of grains, this is in accordance with law of solidification.

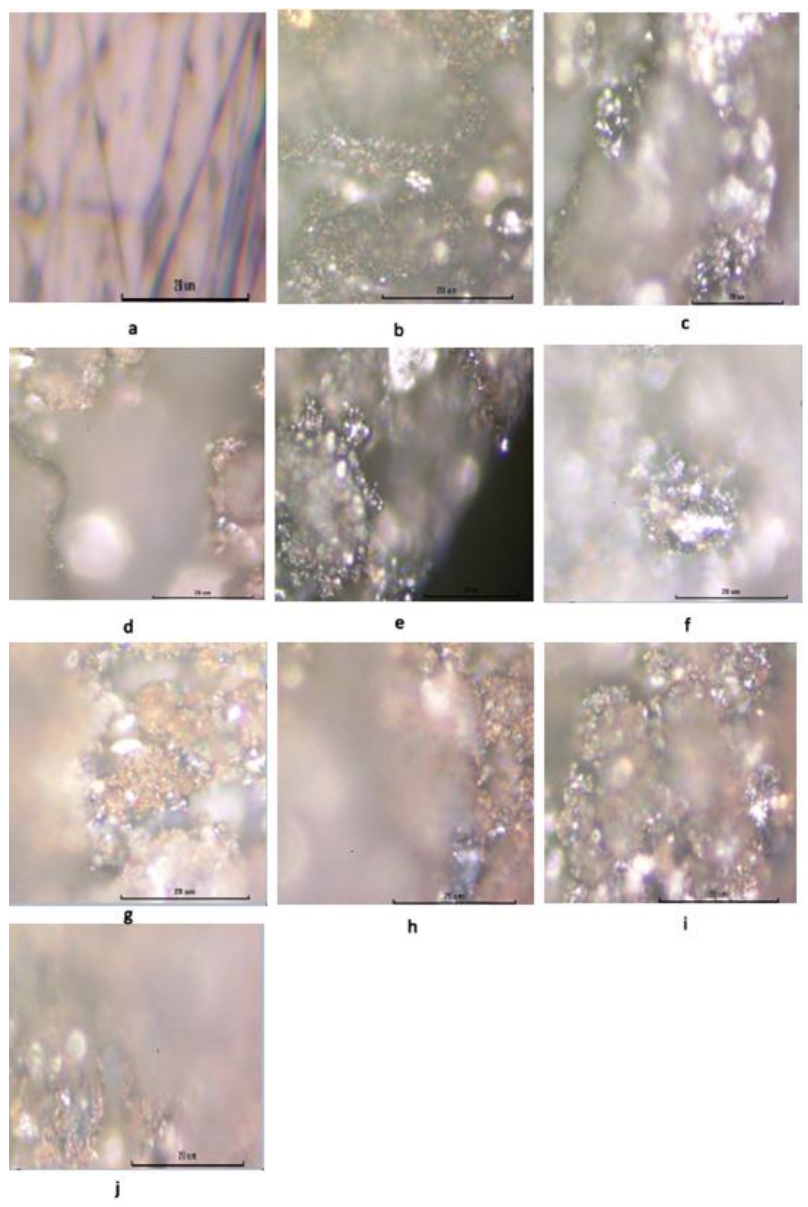

Figure 2. Surface morphology of 304 stainless steel and each group of cladding layers.

\subsection{Wear test analysis of cladding layer}

This article adopts 304 stainless steel and 304 stainless steel weightlessness comparison test of laser cladding, the conditions of the wear test are: The wear test was carried out on double plate metallographic grinding and polishing machine, inversion speed $600 \mathrm{r} / \mathrm{min}$, sand paper adopts $1000 \mathrm{P}$, load holding constant, load time is $3 \mathrm{~min}$, the wear experiment constantly adding water, the test data obtained are shown in Table 3. 
HRC, respectively, as shown in Table4. It is obvious that the hardness of the surfacing layer is better than the substrate.

Table 3. Wear test data

\begin{tabular}{|c|c|c|c|c|}
\hline Materials & $\begin{array}{l}\text { Pre-w } \\
\text { ear } \\
\text { qualit } \\
\text { y(g) }\end{array}$ & $\begin{array}{l}\text { After } \\
\text { wear } \\
\text { qualit } \\
\text { y(g) }\end{array}$ & $\begin{array}{l}\text { Weightlessn } \\
\operatorname{ess}(\Delta g)\end{array}$ & $\begin{array}{l}\text { Weightles } \\
\text { sness } \\
\text { ratio (\%) }\end{array}$ \\
\hline $\begin{array}{l}304 \text { stainless } \\
\text { steel }\end{array}$ & 6.838 & 6.7136 & 0.1244 & 1.82 \\
\hline $\begin{array}{l}\text { 1Ticladding } \\
\text { layer }\end{array}$ & 4.7078 & 4.629 & 0.0778 & 1.65 \\
\hline $\begin{array}{l}0.9 \mathrm{Ti}+0.1 \mathrm{Wc} \\
\text { ladding layer }\end{array}$ & 4.72 & 4.6486 & 0.0714 & 1.51 \\
\hline $\begin{array}{l}0.8 \mathrm{Ti}+0.2 \mathrm{Wc} \\
\text { ladding layer }\end{array}$ & 4.7194 & 4.6495 & 0.0699 & 1.48 \\
\hline $\begin{array}{l}0.7 \mathrm{Ti}+0.3 \mathrm{Wc} \\
\text { ladding layer }\end{array}$ & 4.731 & 4.6633 & 0.0677 & 1.43 \\
\hline $\begin{array}{l}0.6 \mathrm{Ti}+0.4 \mathrm{Wc} \\
\text { ladding layer }\end{array}$ & 6.8516 & 6.7668 & 0.0848 & 1.24 \\
\hline $\begin{array}{l}0.5 \mathrm{Ti}+0.5 \mathrm{Wc} \\
\text { ladding layer }\end{array}$ & 4.742 & 4.6793 & 0.0627 & 1.32 \\
\hline $\begin{array}{l}0.4 \mathrm{Ti}+0.6 \mathrm{Wc} \\
\text { ladding layer }\end{array}$ & 4.763 & 4.6908 & 0.0722 & 1.52 \\
\hline $\begin{array}{l}0.3 \mathrm{Ti}+0.7 \mathrm{Wc} \\
\text { ladding layer }\end{array}$ & 4.7407 & 4.6718 & 0.0689 & 1.45 \\
\hline $\begin{array}{l}0.2 \mathrm{Ti}+0.8 \mathrm{Wc} \\
\text { ladding layer }\end{array}$ & 4.7411 & 4.6645 & 0.0766 & 1.62 \\
\hline
\end{tabular}

The percentage of weight loss $(\%)$ of wear test in table 3 is represented by the broken line Figure 3.

The wear loss of the surfacing layer was measured by HSR-2M reciprocating friction and wear test machine. The change law of the sample wear rate and time was shown in Table 3. As shown by the table, the wear rate was relatively high of untreated steel. Compared with untreated steel, the better wear resistance and smaller changes of wear loss on laser cladding layer. The maximum wear resistant increasing was on $60 \% \mathrm{Ti}$ and $40 \% \mathrm{~W}$ cladding layer.

The Rockwell hardness tests of substrate and laser cladding layer were conducted, as shown in Figure 3. Results of the 3 groups of substrate and laser cladding layer were $42.10,38.50,43.4053,65,62.40$, and 65.73
Table 4. Hardness test result

\begin{tabular}{llll}
\hline Hardness & $\begin{array}{c}\text { Coating } \\
(\text { HRC })\end{array}$ & $\begin{array}{l}\text { layer } \\
\text { 1Ticladding layer }\end{array}$ & $\begin{array}{l}\text { Matrix } \\
\text { layer(HRC) }\end{array}$ \\
\hline $\begin{array}{l}\text { 0.3Ti+0.7Wcladding } \\
\text { layer }\end{array}$ & 63.65 & 42.10 \\
\hline
\end{tabular}

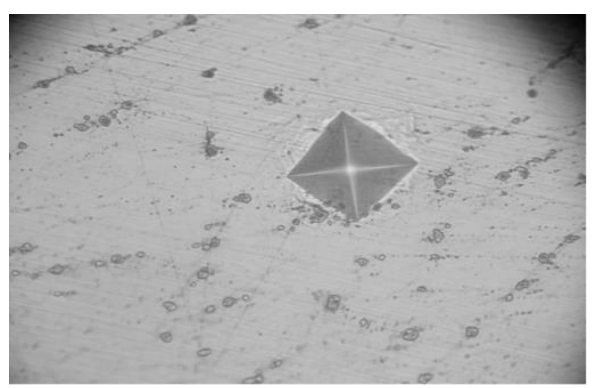

Figure 3. The hardness test of the surfacing layer.

\section{Conclusions}

This paper discussed the influence of laser induced Ti and W coating on stainless steel for wear resistant improvement. The wear resistant of coating was increasing with more tungsten proportion and reached the maximum wear resistant on $40 \%$ Ti and $60 \mathrm{~W}$. After that, the wear resistant decrease but still higher than untreated stainless steel. The hardness of the surfacing layer reached $60 \mathrm{HRC}$, much higher than the hardness of the 304 steel which is about $40 \mathrm{HRC}$, and the coating had better wear resistance much better. The research work in this paper provides some theoretical references for the preparation of composite cladding reinforced of stainless steel surfaces.

\section{References}

1. Z.M. Xu, B.L. Zhang, Y.S. Ji et al. Research on laser improvement of wear-resistant properties of YT carbide blades $[\mathrm{J}]$. Electrical processing and mold, [1989(3)]:33-37.

2. L. Zheng, S.Y. Zhang, K.Q. Zheng. Study on properties of laser cladding cemented carbide 
wc-tin-co[J]. Laser technology, (1994), 18(2):119-122.

3. H.G. Zhu, Q. Yin, R.S. Peng. Effects of High-frequency Microforging on the Laser Cladding Layer prepared on the 304 Stainless Steel Substrate. Laser \& Optoelectronics Progress. (2015); 52(12):121401.

4. S.Y. Zhang, B.B. Wang, K.Q. Zheng. A preliminary study on the mechanism and mechanism of laser cladding wc-tin-sic high carbide $[\mathrm{J}]$. Journal of physics, (1994), 43(4):678-682.

5. J.X. Yang, T.C. Zuo, X.B. Wang et al. Study on laser cladding WC/Ni based cemented carbide tissue structure and wear resistance [J]. Applied laser, (2008), 28(6):450-454.

6. J. Wu, Z.Q. Hang, G.L. Wu et al. Effects of diamond morphological transformation in laser cladding composite coating on coating performance[J]. Application of laser,[ 2015(1)]:14-19.

7. Sahoo CK, Masanta M. Effect of pulse laser parameters on TiC reinforced AISI 304 stainless steel composite coating by laser surface engineering process. Optics and Lasers in Engineering. (2015); 67:36-48.

8. H.B. Xu. Corrosion resistance analysis of $\mathrm{cr}-n$ coatings on 304 stainless steel surfaces[J]. Mechanical engineer, [2015(6)]:133-135.

9. C.Liu, H.S. Chen, Y.F.Liu.Study on sinusoidal reverse vibration synchronous control model of 304 stainless steel crystallizer[J]. Steel vanadium titanium, (2013), 34(2):62-66.

10.Q. Yin, R.S. Peng, H.M.Zhu. In situ laser preparation of Ti(C,N) reinforced iron base coatings on 304 stainless steel surfaces $[\mathrm{J}]$. Thermal processing technology, [2016(8)]:165-168.

11.L.G. Lu, Y.Q. Xia.Development and application of tungsten alloys[J]. China tungsten industry, (2008), 23(3):37-39.

12.Neves D, Diniz AE, Lima MSF.Microstructural analyses and wear behavior of the cemented carbide tools after laser surface treatment and PVD coating. Applied Surface Science. (2013);282:680-8.

13.G.F. Liang, L.Y. Zu, C.Q. Wang et al. In AISI304 stainless steel, in situ observations of convergence [J]. Journal of metals, (2007), 43(2):119-124. 